\title{
Analisis Distribusi Apotek Berdasar Kinerja Standar Pelayanan Kefarmasian Melalui Sistem Informasi Geografis
}

\author{
Analysis of Basic Pharmacy Distribution Performance of Pharmaceutical \\ Services Standards Through Geographic Information Systems
}

\author{
Nura Ali Dahbul*, Nanang Munif Yasin, Lutfan Lazuardi \\ Magister Manajemen Farmasi, Universitas Gadjah Mada \\ Corresponding author: Nura Ali Dahbul: Email: nuradahbul123@gmail.com \\ Submitted: 24-12-2019 Revised: 20-02-2020 Accepted: 02-07-2020
}

\begin{abstract}
ABSTRAK
Apotek sebagai fasilitas kesehatan primer yang menjangkau seluruh lapisan masyarakat. Faktor lokasi apotek berperan dalam kualitas pelayanan dan keberlangsungan bisnis apotek. Tujuan penelitian memberikan gambaran mengenai profil distribusi apotek melalui sistem informasi geografis dari segi aksesibilitas masyarakat dalam pelayanan apotek berdasar standar WHO dan Kemenkes, mengevaluasi pelayanan kefarmasian apotek wilayah Pekalongan sesuai permenkes no 73 tahun 2016 serta evaluasi faktor pertimbangan lokasi dalam proses perijinan apotek. Penelitian berupa cross-sectional menggunakan analisis deskriptif non eksperimental secara kuantitatif. Pengumpulan sampel sejumlah 111 apotek terdiri 55 apotek Kota Pekalongan dan 56 apotek Kabupaten Pekalongan. Analisis distribusi apotek melalui sistem informasi geografis diperoleh melalui visualisasi terhadap peta persebaran apotek Kota dan Kabupaten Pekalongan. Analisis aksesibilitas pelayanan apotek dengan perhitungan rasio antara jumlah apotek dengan jumlah penduduk di setiap kecamatan Kota dan Kabupaten Pekalongan dibandingkan dengan standar WHO yaitu 1:2000 apoteker dan standar Kemenkes yaitu 1: 8.333 apoteker. Evaluasi tentang prosedur pelayanan kefarmasian terdiri dari pengelolaan sediaan farmasi dan pelayanan farmasi klinis sesuai standar Permenkes no 73 tahun 2016. Analisis data dibagi tiga kategori yaitu baik (81-100\%), cukup (61-80\%), dan kurang (20-60\%). Evaluasi faktor pertimbangan melalui wawancara gambaran proses perijinan apotek oleh Dinas Kesehatan dan IAI. Hasil distribusi apotek belum merata di seluruh wilayah Pekalongan. Empat kecamatan di Kabupaten Pekalongan belum berdiri apotek dan banyak apotek terkonsentrasi pada titik tertentu di pusat kota, dekat rumah sakit dan dekat pasar. Hasil aksesibilitas masyarakat terhadap pelayanan apotek, diperoleh lima kecamatan yaitu 47 apotek Kabupaten Pekalongan memenuhi syarat Kemenkes. Hasil pengelolaan obat apotek wilayah Pekalongan kategori cukup yaitu 75,04 \% apotek Kota dan 70,06\% apotek Kabupaten Pekalongan. Hasil pelayanan farmasi klinis di wilayah Pekalongan kategori cukup yaitu 55,32\% apotek Kota Pekalongan dan 57,45\% apotek Kabupaten Pekalongan. Hasil pengelolaan SDM kategori cukup yaitu 82,36\% apotek Kota Pekalongan dan 78,57\% wilayah Kabupaten Pekalongan. Hasil Sarana dan Prasarana kategori cukup yaitu 67,66\% di apotek Kota Pekalongan dan 66,51\% apotek Kabupaten Pekalongan. Evaluasi oleh Dinas kesehatan dan IAI yaitu faktor lokasi sangat berperan penting dalam proses perijinan apotek.
\end{abstract}

Kata kunci: Apotek; Sig; Distribusi apotek; Pelayanan kefarmasian; Pekalongan

\section{ABSTRACT}

Pharmacy as a primary health facility that reaches all levels of society. Pharmacy location factors play a role in the quality of service and business continuity of the pharmacy. The purpose of this study was to provide an overview of the pharmacy distribution profile through geographical information systems in terms of community accessibility in pharmacy services based on WHO and Ministry of Health standards, evaluating pharmacy services in the Pekalongan region according to Permenkes No. 73 of 2016 as well as evaluating location considerations in the pharmacy licensing process. This research was a cross-sectional study using quantitative non-experimental descriptive analysis. Sample collection was 111 pharmacies consisting of 55 pharmacies in Pekalongan City and 56 pharmacies in Pekalongan Regency. Analysis of pharmacy distribution through geographic 
information systems is obtained through visualization of the distribution map of the City and Regency Pekalongan pharmacies. Analysis of pharmacy service accessibility by calculated the ratio between the number of pharmacies and the population in each sub-district of the City and Regency of Pekalongan compared with WHO standards of 1: 2000 pharmacists and Ministry of Health's standard of 1: 8.333 pharmacists. Evaluation of pharmaceutical service procedures consists of managing pharmaceutical preparations and clinical pharmacy services according to Permenkes standard 73 of 2016. Data analysis was divided into three categories: good (81-100\%), sufficient (61-80\%), and less (20-60\%). Evaluation of consideration factors through interviews describing the pharmacy licensing process by the Health Office and IAI. Pharmacy distribution results have not been evenly distributed throughout Pekalongan. Four sub-districts in Pekalongan Regency were not yet have pharmacies and many pharmacies were concentrated at a certain point in the city center, near hospitals and near markets. The results of public accessibility to pharmacy services, obtained five districts, 47 pharmacies Pekalongan Regency meets the requirements of the Ministry of Health. The results of pharmacy drug management in the Pekalongan region are adequate, namely $75.04 \%$ City pharmacies and $70.06 \%$ Pekalongan Regency pharmacies. The results of clinical pharmacy services in the Pekalongan region are sufficient categories, namely 55.32\% Pekalongan City pharmacies and $57.45 \%$ Pekalongan Regency pharmacies. The result of adequate HR management was $82.36 \%$ in the pharmacy in Pekalongan City and $78.57 \%$ in the Pekalongan Regency area. The results of the Facilities and Infrastructure category are sufficient, namely $67.66 \%$ in the pharmacy of Pekalongan City and $66.51 \%$ of pharmacies in Pekalongan Regency. Evaluation by the Department of Health and IAI, which is the location factor plays an important role in the pharmacy licensing process.

Keywords: pharmacy; sig; pharmacy distribution; pharmacy services; pekalongan

\section{PENDAHULUAN}

Pada era revolusi industri 4.0, ilmu pengetahuan dan teknologi berkembang dengan pesat terutama yang berkaitan dengan teknologi informasi. Sistem informasi yang lengkap dan valid sangat diperlukan bagi peningkatan kualitas pelayanan kesehatan. Sistem informasi geografis digunakan sebagai pembuat kebijakan untuk menilai faktor resiko dan mencegah penyakit, dalam rangka menganalisa lokasi geografis sarana kesehatan (Musa, et al., 2013).

Perkembangan ilmu pengetahuan dan teknologi meningkatkan pemahaman masyarakat akan kualitas hidup sehat. Peningkatan taraf hidup sehat sebagai modal utama bagi seseorang dalam menjalankan aktifitasnya. Hal ini mendorong ketersediaan dan keterjangkauan fasilitas pelayanan kesehatan. Penyelenggaraan sarana kesehatan dilakukan oleh pemerintah dan swasta. Sarana kesehatan tersebut antara lain adalah apotek, rumah sakit, puskesmas, klinik kesehatan, praktek pelayanan kesehatan, dan lain-lain.

Dalam hal keterjangkauan pelayanan apotek, melalui sistem informasi geografis profil distribusi lokasi apotek dapat mudah diketahui. Profil distribusi pelayanan kesehatan sangat diperlukan. Sesuai penelitian sebelumnya mengenai jarak antara fasilitas pelayanan kesehatan dengan rumah penduduk mempengaruhi kualitas penanganan pasien tersebut (Yamashita dan Kunkel, 2010).

Pada era Jaminan Kesehatan Nasional saat ini menjadikan Apotek sebagai salah satu fasilitas pelayanan kesehatan yang lebih sering dikunjungi oleh masyarakat pada saat ini namun lokasi apotek kurang merata lebih terkonsentrasi di pusat kota sehingga perlu sistem untuk menganalisa distribusi apotek dilihat dari penyebaran apotek serta aksesibilitas penduduk sekitar terhadap pelayanan apotek khususnya di Pekalongan.

Perencanaan spasial fasilitas kesehatan seperti apotek dapat menjadi salah satu solusi bagi penyebaran fasilitas kesehatan yang tidak merata. Perkembangan ilmu pengetahuan dan teknologi mendorong perlunya suatu sistem komputerisasi untuk menangani masalah tersebut. Sistem Informasi Geografis (SIG) dapat membantu menyajikan data spasial lokasi distribusi apotek (Zaini, 2014).

Apotek merupakan tempat untuk menjalankan pekerjaan kefarmasian bagi apoteker, namun disisi lain apotek juga sebagai ladang bisnis yang memerlukan teknik manajemen untuk dapat menjadikan apotek sebagai tempat yang dapat menghasilkan keuntungan dan tetap berprinsip dengan standar pelayanan kefarmasian. Faktor lokasi sebagai salah satu aspek penting bagi 


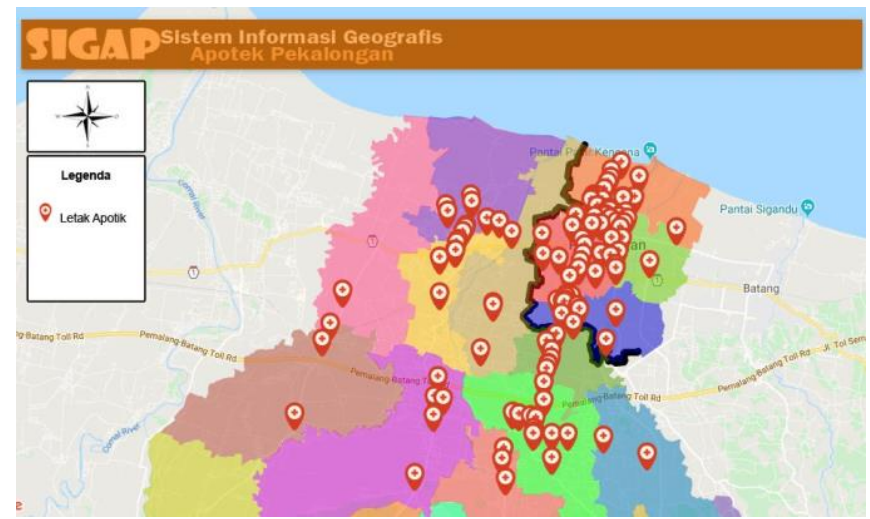

\section{Gambar 1. Peta Persebaran Apotek di wilayah Pekalongan}

keberhasilan suatu apotek, sehingga hal ini berkaitan dengan distribusi jumlah dan pemerataan lokasi apotek. Masyarakat sekitar yang menjadi konsumen apotek dalam memilih layanan sebagai salah satu penentu keberlangsungan suatu apotek selain faktor pengaruh lainnya dalam manajemen pemasaran suatu fasilitas layanan apotek. Keterjangkauan masyarakat dengan apotek, pelayanan baik apotek, kelengkapan obat, harga obat yang relatif murah, serta adanya kerjasama dengan dokter, serta terutama apotek yang telah menerapkan standar pelayanan kefarmasian dengan total akan menjadi keunggulan tersendiri bagi apotek tersebut.

Pemenuhan standar merupakan suatu cara untuk penjaminan mutu. Menteri kesehatan mengeluarkan Permenkes No. 73 tahun 2016 tentang Standar Pelayanan Kefarmasian di Apotek sebagai pedoman praktik apoteker dalam menjalankan tugas profesi, untuk melindungi masyarakat dari pelayanan yang tidak profesional, dan melindungi profesi dalam menjalankan praktik kefarmasian. Berdasarkan hasil beberapa penelitian sebelumnya mengenai pelaksanaan standar pelayanan kefarmasian di apotek menunjukkan fakta apotek di Indonesia banyak yang belum menerapkan standar pelayanan kefarmasian dengan baik. Seperti penelitian mengenai pelaksanaan standar pelayanan kefarmasian di apotek Kota Yogyakarta menunjukkan hanya $21 \%$ apoteker yang melaksanakan standar pelayanan kefarmasian dengan baik (Atmini dkk, 2011).

\section{METODE PENELITIAN}

Rancangan penelitian ini berupa analisa deskriptif non eksperimental. Metode penelitian yang digunakan adalah metode pendekatan secara kuantitatif. Data diperoleh dengan teknik, yaitu kuesioner, observasi lapangan, wawancara, dan dokumentasi. Observasi lapangan dilakukan untuk memperoleh titik koordinat apotek yang akan diolah bersama dengan data sekunder (hasil dokumentasi) menggunakan sistem informasi geografis sehingga diperoleh gambaran profil distribusi apotek. Aksesibilitas penduduk diperoleh dengan membandingkan tingkat kepadatan penduduk di setiap kecamatan dengan jumlah apotek yang ada dibandingkan dengan standar WHO dan Kemenkes. Penerapan standar pelayanan kefarmasian di apotek melalui metode kuesioner ke apotek. Wawancara mendalam dilakukan terhadap Kepala Dinas kesehatan kota dan kabupaten Pekalongan melalui kepala seksi Pelayanan Kefarmasian, Ketua IAI Kota dan Kabupaten Pekalongan untuk melihat faktor pertimbangan dalam pemilihan lokasi apotek.

\section{HASIL DAN PEMBAHASAN}

Penelitian ini menggambarkan profil persebaran apotek di Kota dan Kabupaten Pekalongan berdasarkan pemetaan lokasi apotek melalui Sistem Informasi Geografis. Wilayah Pekalongan memiliki 134 apotek yang tersebar 62 apotek di Kota Pekalongan dan 72 apotek di Kabupaten Pekalongan. Gambaran tentang distribusi apotek menggunakan data lokasi koordinat tiap apotek yang diperoleh dari GPS (Gambar 1).

Dari gambar diatas dapat disimpulkan persebaran apotek terutama di jalan utama yang menghubungkan Kota dan Kabupaten Pekalongan terdapat sekitar 35 titik lokasi apotek yang terletak dari arah selatan 
Tabel I. Rasio Jumlah Apotek dengan Jumlah Penduduk Kab. Pekalongan

\begin{tabular}{|c|c|c|c|c|c|}
\hline \multirow{2}{*}{ Kecamatan } & \multicolumn{2}{|c|}{ Jumlah Apotek } & \multirow{2}{*}{$\begin{array}{c}\text { Jumlah } \\
\text { penduduk }\end{array}$} & \multirow{2}{*}{$\begin{array}{c}\text { Luas } \\
\text { wilayah }\left(\mathrm{km}^{2}\right)\end{array}$} & \multirow{2}{*}{$\begin{array}{l}\text { Kepadatan } \\
\text { Penduduk }\end{array}$} \\
\hline & $\sum$ & $\%$ & & & \\
\hline Bojong & 4 & 5,55 & 62.460 & 40,06 & 1,56 \\
\hline Buaran & 6 & 8,33 & 42.495 & 09,54 & 4,45 \\
\hline Doro & 1 & 1,39 & 37.071 & 68,45 & 0,54 \\
\hline Kajen & 10 & 13,89 & 58.048 & 75,15 & 0,77 \\
\hline Karanganyar & 3 & 4,17 & 35.698 & 63,43 & 0,56 \\
\hline Karangdadap & 2 & 2,78 & 33.413 & 20,99 & 1,59 \\
\hline Kedungwuni & 16 & 22,22 & 90.774 & 22,94 & 3,95 \\
\hline Kesesi & 2 & 2,78 & 61.228 & 68,51 & 0,89 \\
\hline Paninggaran & 2 & 2,78 & 34.221 & 92,99 & 0,37 \\
\hline Sragi & 3 & 4,17 & 60.665 & 32,40 & 1,87 \\
\hline Tirto & 4 & 5,55 & 65.002 & 17,39 & 3,74 \\
\hline Wiradesa & 10 & 13,89 & 56.065 & 12,71 & 4,41 \\
\hline Wonokerto & 5 & 6,94 & 43.735 & 15,90 & 2,75 \\
\hline Wonopringgo & 3 & 4,17 & 41.186 & 17,00 & 2,42 \\
\hline Siwalan & 1 & 1,39 & 37.573 & 28,91 & 1,29 \\
\hline Talun & 0 & 0 & 25.412 & 58,57 & 0,43 \\
\hline Petungkriyono & 0 & 0 & 11.882 & 73,58 & 0,16 \\
\hline Lebak barang & 0 & 0 & 9.885 & 58,20 & 0,17 \\
\hline Kandangserang & 0 & 0 & 31.808 & 60,68 & 0,52 \\
\hline Jumlah & 72 & & 934.929 & 836.13 & 1,11 \\
\hline
\end{tabular}

dikabupaten Pekalongan kecamatan doro hingga arah utara di Kota Pekalongan kecamatan Pekalongan utara. Serta mengelompok pada suatu pusat fasilitas pelayanan seperti pasar dan rumah sakit

Dari tabel I jumlah apotek di wilayah Pekalongan tidak tersebar secara merata terutama di kabupaten Pekalongan pada 4 kecamatan belum terdapat apotek yaitu Lebakbarang, Kandangserang, Petungkriyono dan Talun.

Hal ini disebabkan oleh lokasi kecamatan yang lebih jauh dari pusat kota dan infrastruktur masih belum sempurna. Para warga lebih cenderung berobat ke puskesmas atau ke dukun pijat dan mungkin mencari apotek di kecamatan tetangga. Hal ini menjadi peluang lebih lanjut untuk mendirikan apotek di lokasi tersebut. Apotek terbanyak berada di kecamatan kedungwuni berjumlah 16 apotek.

Di beberapa negara maju seperti Inggris, Finlandia, Perancis, Norwegia dan Australia, pengaturan lokasi apotek dilakukan oleh pemerintah supaya distribusi dan jumlah apotek lebih merata demi meningkatkan pelayanan kesehatan (Consumers Health Forum of Australia, 2010).

Untuk wilayah Kota Pekalongan lebih merata namun lebih banyak mengelompok di kecamatan Pekalongan Utara dijelaskan dalam tabel II.

Kepadatan penduduk tertinggi berada pada kecamatan Pekalongan Barat dan kecamatan dengan kepadatan penduduk terendah adalah kecamatan Pekalongan Utara. Hasil tersebut memperlihatkan bahwa kecamatan Pekalongan Utara dengan jumlah apotek terbanyak belum berarti merupakan wilayah dengan penduduk yang paling padat. Wilayah Kota Pekalongan cenderung merata walaupun lebih banyak mengelompok di Pekalongan Utara, dikarenakan pusat perekonomian di Kota Pekalongan lebih condong di daerah Pekalongan Utara namun kondisi geografisnya tidak sejalan dikarenakan kondisi air laut yang sering naik menyebabkan sering terjadinya banjir.

Aksesibilitas Pelayanan apotek

World Health Organization (WHO) menjelaskan mengenai standar jumlah apoteker yang dapat memberikan pelayanan kepada penduduk di suatu wilayah. Pencapaian pelayanan kefarmasian disuatu wilayah dinilai dari rasio jumlah apoteker terhadap jumlah penduduk yaitu 50 :100.000 penduduk (Azhar et al., 2009; Ghani et al., 2010).

Indonesia telah menerapkan aturan yang dikeluarkan Kementrian Kesehatan yang 
Tabel II. Rasio jumlah Apotek Kota Pekalongan terhadap JumlahPenduduk

\begin{tabular}{llcccc}
\hline \multicolumn{1}{c}{ Kecamatan } & \multicolumn{2}{c}{ Jumlah Apotek } & $\begin{array}{c}\text { Jumlah } \\
\text { penduduk }\end{array}$ & $\begin{array}{c}\text { Luas } \\
\text { wilayah }\end{array}$ & $\begin{array}{c}\text { Kepadatan } \\
\text { penduduk }\end{array}$ \\
\cline { 2 - 3 } & $\sum$ & $\mathbf{\%}$ & 94.881 & 10,05 & 9.441 \\
\hline $\begin{array}{l}\text { Pekalongan } \\
\text { Barat }\end{array}$ & 14 & 22,58 & & & 6.887 \\
$\begin{array}{l}\text { Pekalongan } \\
\text { Timur }\end{array}$ & 13 & 20,97 & 65.563 & 9,52 & 5.758 \\
$\begin{array}{l}\text { Pekalongan } \\
\text { Selatan }\end{array}$ & 14 & 22,58 & 62.186 & 10,8 & 5.500 \\
$\begin{array}{l}\text { Pekalongan } \\
\text { Utara }\end{array}$ & 21 & 33,87 & 81.847 & 14,88 & 6.729 \\
\hline
\end{tabular}

Tabel III. Standar Aksebilitas Pelayanan Apotek di Kabupaten Pekalongan

\begin{tabular}{lcccc}
\hline Kecamatan & $\begin{array}{c}\text { RasiojmlPenduduk: } \\
\text { Standar WHO (1:2000)}\end{array}$ & Hasil & $\begin{array}{c}\text { RasiojmlPenduduk: } \\
\text { Standar Kemkes } \\
\mathbf{( 1 : 8 . 3 3 3 )}\end{array}$ & Hasil \\
\hline Bojong & $32: 62.460$ & TT & $7: 62.460$ & TT \\
Buaran & $21: 42.495$ & TT & $5: 42.495$ & T \\
\hline Doro & $18: 37.071$ & TT & $4: 37.071$ & TT \\
Kajen & $29: 58.048$ & TT & $7: 58.048$ & T \\
Karanganyar & $18: 35.698$ & TT & $4: 35.698$ & TT \\
Karangdadap & $17: 33.413$ & TT & $4: 33.413$ & TT \\
Kedungwuni & $45: 90.774$ & TT & $11: 90.774$ & T \\
Kesesi & $31: 61.228$ & TT & $7: 61.228$ & TT \\
Paninggaran & $17: 34.221$ & TT & $4: 34.221$ & TT \\
Sragi & $30: 60.665$ & TT & $7: 60.665$ & TT \\
Tirto & $32: 65.002$ & TT & $7: 65.002$ & TT \\
Wiradesa & $28: 56.065$ & TT & $7: 56.065$ & T \\
Wonokerto & $22: 43.735$ & TT & $5: 45.733$ & T \\
Wonopringgo & $20: 41.186$ & TT & $5: 41.186$ & TT \\
Siwalan & $19: 37.573$ & TT & $4: 37.573$ & TT \\
Talun & $13: 25.412$ & TT & $3: 25.412$ & TT \\
Petungkriyono & $6: 11.882$ & TT & $1: 11.882$ & TT \\
Lebak barang & $5: 9.885$ & TT & $1: 9.885$ & TT \\
Kandangserang & $16: 31.808$ & TT & $4: 31.808$ & TT \\
Jumlah & $419: 934.929$ & 72 & $98: 934.929$ & 72 \\
\hline
\end{tabular}

mengatur mengenai rasio apoteker terhadap jumlah penduduk yaitu dikatakan memenuhi jika nilainya 12 : 100.000 penduduk (BKKBN, 2012). Rasio jumlah apoteker dengan jumlah penduduk dapat diasumsikan untuk menentukan ketercapaian pelayanan kefarmasian apotek berbanding jumlah penduduk berdasarkan aturan WHO dan Kementrian Kesehatan tersebut, mengingat satu apotek setidaknya memiliki satu apoteker (Zaini, 2014).

Seluruh Kecamatan di Kabupaten Pekalongan tidak terpenuhi oleh standar dari
WHO, hal ini disebabkan oleh perbedaan kondisi geografis wilayah dan administrasi penduduk serta kondisi perekonomian yang berbeda antara standar WHO yang lebih condong di Negara Maju.

Hasil yang diperoleh dari tabel III, terdapat lima Kecamatan yang telah terpenuhi standar oleh Kemenkes yaitu minimal satu apotek per 8.333 jumlah penduduk di suatu Kecamatan. Rasio apotek yang paling kecil di wilayah kedungwuni yaitu 1 apotek dibandingkan 5.673 jumlah penduduk disebabkan dengan jumlah penduduk yang 
Tabel IV. Standar Aksebilitas Pelayanan Apotek di Kota Pekalongan

\begin{tabular}{lcccc}
\hline Kecamatan & $\begin{array}{c}\text { RasiojmlPenduduk: } \\
\text { Standar WHO } \\
\mathbf{( 1 : 2 0 0 0 )}\end{array}$ & Hasil & $\begin{array}{c}\text { RasiojmlPenduduk: } \\
\text { StandarKemkes } \\
\mathbf{( 1 : 8 . 3 3 3 )}\end{array}$ & Hasil \\
\hline Pekalongan Barat & $47: 94.881$ & TT & $11: 94.881$ & $\mathrm{~T}$ \\
Pekalongan Timur & $33: 65.563$ & TT & $8: 65.563$ & $\mathrm{~T}$ \\
Pekalongan Selatan & $31: 62.186$ & TT & $7: 62.186$ & $\mathrm{~T}$ \\
Pekalongan Utara & $41: 81.847$ & TT & $10: 81.847$ & $\mathrm{~T}$ \\
Total & $152: 304.477$ & & & \\
\hline
\end{tabular}

Tabel V. Total Standar Pelayanan Kefarmasian Apotek

\begin{tabular}{ccc}
\hline Standar & Apotek Kota & Apotek Kabupaten \\
\hline pengelolaan & 75,05 & 70,06 \\
farmasi klinis & 55,32 & 57,45 \\
sdm & 82,36 & 78,57 \\
sarana dan prasarana & 67,66 & 66,51 \\
TOTAL & 70,09 & 68,15 \\
\hline
\end{tabular}

paling banyak di Kabupaten Pekalongan yaitu sebesar 90.774 jumlah penduduk dengan jumlah apotek yang paling banyak yaitu 16 apotek. Kecamatan Kedungwuni sudah sejak dahulu menjadi pusat perekonomian di Kabupaten Pekalongan, namun tidak menjadikan alasan sebagai Kabupaten Pekalongan, letak Kecamatan Kedungwuni yang mudah diakses dari seluruh kecamatan di Kabupaten Pekalongan. Kaitannya dengan standar WHO, data di Kabupaten Pekalongan masih jauh dibawah standar. Hal ini dijelaskan lebih lanjut pada tabel IV sebagai pembanding antara standar dari WHO dan Kemenkes.

Standar WHO dan Kemenkes dalam jumlah apotek dibanding dengan jumlah penduduk Kota Pekalongan dijelaskan lebih lanjut pada tabel IV.

Setiap Kecamatan di Kota Pekalongan telah memnuhi standar dari Kemenkes dilihat dari jumlah apotek di setiap kecamatan yang cukup banyak dibandingkan jumlah penduduk yang hanya kurang lebih sepertiga jumlah penduduk Kabupaten Pekalongan. Terutama di Pekalongan Selatan hanya memenuhi standar Kemenkes sejumlah 7 apotek namun kenyataannya ada 14 apotek berada di wilayah Pekalongan Selatan. Hal ini dapat menjadi gambaran bagaimana menjaga kelangsungan bisnis masing-masing apotek serta menjaga hubungan antar teman sejawat apoteker. Hal ini juga terjadi Pekalongan Utara yang hanya memenuhi standar Kemenkes yaitu sejumlah 10 apotek namun ada 21 apotek yang berdiri di wilayah Pekalongan Utara.

Evaluasi Pelaksanaan Standar Pelayanan Kefarmasian di apotek

Pelayanan kefarmasian di apotek dikerjakan oleh apoteker penanggung jawab apotek dengan bantuan apoteker pendamping atau TTK (Tenaga Teknis Kefarmasian) jika APA tidak bekerja fulltime di apotek (Pemerintah Republik Indonesia, 2016). Pada penelitian ini, ada beberapa apotek yang telah memiliki apoteker pendamping namun kebanyakan apotek masih menggunakan tenaga non teknis lulusan SMK Farmasi yang seharusnya menurut PMK standar pelayanan no 73 tahun 2016 bahwa TTK minimal lulusan D3 Farmasi.Hal ini diakibatkan kurangnya minat lulusan D3 Farmasi untuk bekerja di apotek diakibatkan oleh penurunan omset apotek di beberapa wilayah berkenaan dengan era JKN saat ini yang hampir seluruh pelayanan kesehatan berupa pencegahan dan pengobatan masyarakat dieksklusifkan ke dalam fasilitas kesehatan yang telah bekerjasama dengan BPJS. Dari total data kuesioner yang diperoleh dihitung berdasarkan standar pelayanan kefarmasian dijelaskan dalam tabel $\mathrm{V}$.

Untuk evaluasi penerapan Permenkes no 73 tahun 2016 tentang prosedur pelayanan kefarmasian terdiri dari pengelolaan sediaan farmasi dan pelayanan farmasi klinis. Analisis data kuantitatif dilakukan menggunakan skala 
Guttman. Kemudian dibagi tiga kategori yaitu baik (81-100\%), cukup (61-80\%), dan kurang (20-60\%). Hasil penelitian diperoleh rerata tingkat pengelolaan obat 75,05\% pada apotek kota dan 70,06 pada apotek di kabupaten Pekalongan, pelayanan farmasi klinis 55,32\% apotek kota Pekalongan dan 57,45\% di wilayah kabupaten Pekalongan, pengelolaan SDM 82,36\% wilayah kota Pekalongan dan 78,57\% wilayah kabupaten Pekalongan. Sarana dan prasarana kota Pekalongan 67,66\% dan 66,51\% di kabupaten Pekalongan. Dapat disimpulkan bahwa tingkat penerapan standar pelayanan kefarmasian di apotek termasuk dalam kategori cukup. Pelayanan farmasi klinis di wilayah Pekalongan termasuk dalam kategori kurang.

\section{KESIMPULAN}

Persebaran di apotek wilayah Kota dan Kabupaten Pekalongan belum terdistribusi merata. Dilihat dari peta distribusi apotek lebih mengelompok di suatu titik pemukiman didekat perkotaan dan titik tertentu saja seperti Rumah sakit, pasar, dan titik pusat keramaian lainnya.aksesibiltasapotek di wilayah Pekalongan belum memenuhi standar WHO. Lima kecamatan di kabupaten Pekalongan telah memenuhi standar Kemkes dan semua Kecamatan di Kota Pekalongan telah memenuhi standar Kemkes. Gambaran pelayanan kefarmasiaan di apotek wilayah Pekalongan belum sepenuhnya berjalan sempurna dan termasuk dalam kategori cukup dalam analisa guttman bernilai 70,09 \% untuk apotek Kota Pekalongan dan 68,15\% apotek Kabupaten Pekalongan.

\section{UCAPAN TERIMAKASIH}

Terimakasih kepada Dr. Nanang Munif Yasin, M.Pharm, Apt, dr. Lutfan Lazuardi, M.kes, PhD., Dr. Satibi, M.Si, Apt, Dr. Susi Ari Kristina., M.Kes, Apt. Serta kepada semua pihak yang terlibat dalam penelitian ini.

\section{DAFTAR PUSTAKA}

Atmini, K. D., Gandjar, I. G., Purnomo, A., 2011, Analisis Aplikasi Standar Pelayanan Kefarmasian Di Apotek Kota Yogyakarta, Jurnal Manajemen dan Pelayanan Farmasi, Volume 1 Nomor 1, Yogyakarta.

Azhar, S., Hassali, M.A.,Ibrahim, M.IM.,Ahmad, M, Massod, I.,and Shafie, A.A. 2009, Review : The Role og Pharmacist in Developing Countries : The Current Senario in Pakistan. Human Resource for Health, 7:54

BKKBN, 2012, Kebijakan dan Strategi Pengembangan dan Pemberdayaan SDM Kesehatan,http://www.bkkbn.go.id/mat eri/Documents/Materi\%20Rakernas\%2 0 2012/PPSDM\%20BKKBN.pdf, diakses tanggal 28 Agustus 2019.

Ghani, K.,Gillani, W., and Ghani, M. 2010, Pharmacy Teaching and Practices

Problems in Developing Countries : Review. International Journal of Pharmacy

Teaching and Practice, 1(1):11-17.

Musa, G.J., Chiang, P.H., Sylk, T., Bavley, R., Keating, W., Lakew, B., Tsou, H.C., Hoven, C.W., 2013, Use of GIS Mapping as a Public Health Tool-From Cholera to Cancer, Health Services Insight, pp 111-116, New York City, USA.

Permenkes RI 9, 2017, Peraturan Menteri Kesehatan Republik Indonesia nomor 73 tahun 2016 tentang Apotek, Presiden Republik Indonesia, Jakarta.

Yamashita T, and Kunkel SR, 2010.The Association Between Heart Disease Mortality and Geographic Access to Hospital: Country Level Comparisons in Ohio USA, Social Science \& Medicine 70:1211-1218.

Zaini, M., 2014, Analisis Niat Konsumen Dalam Pemanfaatan Pelayanan Apotek, Tesis, M.sc., Universitas Gadjah Mada. 